Research Paper

\title{
The Association of BCG Vaccination with Atopy and Asthma in Adults
}

\author{
Sung Soo Park ${ }^{1}$, Eun Young Heo ${ }^{1}$, Deog Kyeom Kim ${ }^{1}$, Hee Soon Chung1ㅜ, Chang-Hoon Lee ${ }^{1,2}$ \\ 1. Division of Pulmonary and Critical Care Medicine, Department of Internal Medicine, Seoul National University College of Medicine, \\ Seoul Metropolitan Government Seoul National University Boramae Medical center, Seoul, Republic of Korea \\ 2. Division of Pulmonary and Critical Care Medicine, Department of Internal Medicine, Seoul National University College of Medicine, \\ Seoul National University Hospital, Seoul, Republic of Korea
}

$\triangle$ Corresponding author: Chang-Hoon Lee, MD. Current address: Associate professor, Division of Pulmonary and Critical Care Medicine, Department of Internal Medicine, Seoul National University College of Medicine, Seoul National University Hospital, 101 Daehak-Ro, Jongno-Gu, Seoul 110-744, Korea. Telephone: 82-2-2072-4743, Fax 82-2-762-9662, E-mail: kauri670@empal.com

(C) 2015 Ivyspring International Publisher. Reproduction is permitted for personal, noncommercial use, provided that the article is in whole, unmodified, and properly cited. See http://ivyspring.com/terms for terms and conditions.

Received: 2015.03.24; Accepted: 2015.07.18; Published: 2015.08.01

\begin{abstract}
Introduction: There are few studies investigating the association between BCG vaccination and atopy or asthma in adults.

Objective: We investigated the association between BCG scar and the occurrence of atopy and asthma in Korean adults.

Methods: We carried out a retrospective study of Korean adults who underwent skin prick testing, and, in some cases, spirometry and bronchial provocation tests in a secondary care hospital from April 2010 to February 2011. Atopy status was classified according to allergen/histamine $(A / H)$ ratio of wheal $(A / H$ ratio $\geq 1$, atopy; $0<A / H$ ratio $<1$, intermediate; $A / H$ ratio $=0$, non-atopy). A patient with asthma was defined as one who has symptoms compatible with asthma and showed either a positive provocation testing or bronchodilator reversibility.

Results: Among 200 participants, neither the presence (intermediate vs. non-atopy: adjusted odds ratio (aOR) $0.83 ; 95 \% \mathrm{Cl} 0.26,2.60 ; \mathrm{p}=0.75$, atopy vs. non-atopy: aOR 0.89; $95 \% \mathrm{Cl} 0.33,2.37 ; \mathrm{p}$ $=0.81$, respectively). nor the size of BCG scar was significantly associated with atopy status. However, among those patients who underwent either bronchodilator response testing or bronchial provocation testing, the presence of BCG scar (aOR 0.33; $\mathrm{Cl} 0.14,0.77 ; \mathrm{p}=0.01$ ) and the size of BCG scar were inversely associated with asthma. $(p=0.01)$

Conclusions: We found a significant association between BCG scar and asthmatic status in Korean adults, although there was no significant association between either the presence or size of BCG scar and atopy.
\end{abstract}

Key words: BCG vaccine, atopy, asthma, hygiene

\section{Introduction}

The hygiene hypothesis attempts to explain the increase in the prevalence of asthma in developed countries during the past decades. This hypothesis states that the relative lack of infections early in life may promote the development of allergic diseases in genetically predisposed individuals [1, 2]. Shirakawa et al.[3], one of the studies generating the hygiene hypothesis, reported an inverse reported that exposure to mycobacteria and size of tuberculin response was inversely associated with subsequent atopy in Japanese children.

Various studies have examined whether early exposure to microbial products modulates the immune system in a manner that opposes the mecha- 
nisms related to the development of atopy, with negative results or results of limited impact, in contrast to the general expectation [4-10]. However, results seem to vary when studying populations from different ethnic backgrounds. For example, some investigators have shown that bacillus Calmette-Guérin (BCG) immunization offers some protection against atopy in some immigrant populations in western countries [6, 9] or in less developed countries such as Guinea-Bissau [4]. However, some investigations have demonstrated different results $[7,8]$.

There are few studies investigating the association between BCG vaccination and atopy or asthma in adults. It is unknown if the protection provided by BCG vaccination in preventing the development of allergy can extend to adulthood or whether the memory of the immune system and the capability of polarizing T-lymphocytes may be greater in early life and subsides gradually with age [11]. Although BCG vaccination was reported not to cause long-term induction of a Th1 response in some asthmatic children [12], there is some evidence that even a single dose of an effective BCG vaccine can provide long-term protection against tuberculosis (TB) $[13,14]$.

In South Korea, it has been recommended that all newborn babies be vaccinated with BCG within four weeks after birth, as the incidence of tuberculosis is relatively high. The primary objective of this study is to determine whether BCG vaccination is associated with the presence of atopy and asthma in Korean adults, using the BCG scar size as an indicator of response to the BCG vaccine.

\section{Materials and Methods}

\section{Study population}

Adults aged 18-86 years who visited the pulmonology department because of respiratory symptoms in a secondary referral hospital and underwent skin prick testing (SPT) from April 2010 to February 2011 were enrolled in this retrospective study. We excluded participants who had any condition known to cause anergy of $\mathrm{T}$ lymphocytes (severe malnutrition, immunosuppression by disease or drugs, occurrence of episodes of fever, administration of live virus vaccines in the previous 30 days) or who did not comply with washout of medications that would interfere with spirometry and bronchial provocation tests at the time of the study. The study was approved by the Institutional Review Board of our institute.

\section{Skin prick testing and measurement of BCG scar size}

SPT was performed for 38 common aeroallergens (Allergopharma, Reinbek, Germany) on the back of each subject. After 15 minutes, the largest diameter of each wheal was measured, as well as the diameter at 90 degrees to the largest diameter. An SPT result was considered positive if the average measurement of the wheal of any allergen was equal to or larger than positive control (histamine). When the allergen/histamine $(\mathrm{A} / \mathrm{H})$ ratio of wheal to any aeroallergen was equal or greater than 1 , the patient was considered to have atopy. The subject was classified as non-atopic if the $\mathrm{A} / \mathrm{H}$ ratio was 0 . The remainder of the subjects $(0<\mathrm{A} / \mathrm{H}$ ratio $<1)$ were defined as the intermediate group.

In our hospital, the BCG scar status of patients who visit the pulmonology department has been routinely examined and recorded since 2009. The subjects were checked for BCG scars on their arms, the transverse and longitudinal diameters of BCG scars were also measured by the same examiner using a transparent millimeter ruler and the average scar size was calculated. Chest radiographs from the subjects, if available, were reviewed for pulmonary TB sequelae.

\section{Pulmonary function tests \& methacholine/mannitol challenge}

We evaluated the results from spirometry and bronchial provocation testing conducted within one month from the date of SPT. Patients underwent standard spirometry (Vmax series 2130; Sensor Medics, Yorba Linda, CA, USA) according to the recommendations presented in the Guidelines of the American Thoracic Society. Bronchodilator reversibility was defined as an increase in forced expiratory volume in 1 second $\left(\mathrm{FEV}_{1}\right)>12 \%$ baseline and $200 \mathrm{ml}$ above the prebronchodilator baseline, 30 minutes after the inhalation of $200 \mu \mathrm{g}$ salbutamol via a metered-dose inhaler.

Inhaled mannitol was delivered using a commercial preparation (AridolTM, Pharmaxis Ltd, Frenchs Forest, NSW, Australia). Increasing doses of mannitol $(0,5,10,20,40,80,160,160,160 \mathrm{mg})$ were inhaled via a dry powder inhaler until either a total cumulative dose of $635 \mathrm{mg}$ was administered or until a $15 \%$ fall in $\mathrm{FEV}_{1}$ from baseline was observed 60 seconds after dosing. Airway sensitivity was expressed as the cumulative provoking dose of mannitol to cause a $15 \%$ fall in $\mathrm{FEV}_{1}$ (PD15). If a subject experienced a drop in $\mathrm{FEV}_{1}$ from baseline of greater than or equal to $15 \%$ before or immediately after administration of the final dose, the test was considered positive. The inability to achieve a $15 \%$ fall from baseline or greater in $\mathrm{FEV}_{1}$ by the final dose the test was considered a negative result.[15] Methacholine (Methapharm, Brantford, Ontario, Canada) was administered using an aerosol dosimeter at 5 minute intervals in increasing doses from $0.15 \mathrm{mg} / \mathrm{ml}$ to 25 
$\mathrm{mg} / \mathrm{ml}$ until a $20 \%$ reduction in $\mathrm{FEV}_{1}$ was recorded. The provoking concentrations of methacholine required to produce a $20 \%$ fall in $\mathrm{FEV}_{1}$ from the pre-challenge value (PC20) was determined by interpolation. [16] The challenges were separated into positive test results (PC20 $\leq 25 \mathrm{mg} / \mathrm{ml}$ ) and negative test results (PC20 $>25 \mathrm{mg} / \mathrm{ml})$. A patient with asthma was defined as one who has symptoms compatible with asthma and showed either a documented airway hyper-responsiveness (PC20 methacholine $\leq 25$ $\mathrm{mg} / \mathrm{mL}$ or PD15 mannitol $\leq 635 \mathrm{mg}$ ) or bronchodilator reversibility.

\section{Statistical analysis}

Chi-squared tests, Fisher's exact test, linear-by-linear association or Kruskal-Wallis test, if appropriate, were used to compare the differences in prevalence or continuous variables among groups. For multivariable analysis, the multinomial logistic regression model was used to evaluate the association between atopy status (atopy, intermediate, and non-atopy groups) and status of the BCG scar (both presence and size of scar), with adjustment for potential confounding factors. In addition, binary logistic regression analysis was used to elucidate whether asthma status (asthma or non-asthma group) has an association with the status of BCG scar. Analyses were repeated excluding those with old TB scars because tuberculosis is associated with protection from atopy and asthma [3].

A $P$ value of less than 0.05 was considered statistically significant. Statistical computations were performed using the SPSS software version 17.0 (SPSS, Chicago, IL, USA).

\section{Results}

In total, two hundred adult subjects were enrolled in the study. Among these subjects, 156 (78.0\%) had a BCG scar. The BCG scar group was younger than no BCG scar group. There were no statistically significant differences in sex, the presence of stable old tuberculosis scar in chest radiograph between two groups (Table 1).

The presence of a BCG scar was not significantly associated with reduced risk for an individual to be categorized as intermediate or atopic (intermediate vs. non-atopy: adjusted odds ratio (aOR) $0.83 ; 95 \% \mathrm{CI}$ $0.26,2.60 ; \mathrm{p}=0.75$, atopy vs. non-atopy: aOR $0.89 ; 95 \%$ CI 0.33, 2.37; $\mathrm{p}=0.81$, respectively). The statistical power was calculated as $45.3 \%$. We observed that older patients had a lower risk of developing atopy (intermediate vs. non-atopy: aOR for every one year of age $0.97 ; 95 \%$ CI $0.94,1.00 ; \mathrm{p}=0.05$, atopy vs. non-atopy: aOR for every one year of age $0.91 ; 95 \% \mathrm{CI}$ $0.89,0.94 ; \mathrm{p}<0.01$, respectively). The mean diameter of BCG scar was not associated with risk of atopy, after adjusting for age and sex (Table 2).

Among those participants who underwent either bronchodilator response testing or bronchial provocation test, the presence of a BCG scar was inversely associated with asthma (aOR 0.33; CI 0.14, 0.77; $\mathrm{p}=$ 0.01). Fewer asthmatic patients were observed with larger scar size (aOR 0.94; CI 0.89, 0.99; $\mathrm{p}=0.01)$. (Table 3)

Subgroup analyses including subjects who showed no old tuberculosis scars on chest radiographs $(n=132)$ revealed similar results (data not shown). The scar size was also investigated as a binary variable comparing large $(\geq 5 \mathrm{~mm})$ vs. small $(<5$ $\mathrm{mm}$ ), which did not change the results.

Table 1. The characteristics of the study population according to the presence of BCG scar.

\begin{tabular}{|c|c|c|c|}
\hline Variables & BCG scar $(+)(n=156)$ & BCG scar $(-)(n=44)$ & p-value \\
\hline Age, years, median (IQR) & $35.50(29.25-50.00)$ & $56.50(31.50-68.75)$ & $<0.01$ \\
\hline Women $(\%)$ & $79 / 156(50.6 \%)$ & $24 / 44(54.5 \%)$ & 0.65 \\
\hline Diameter of BCG scar, mm, median (IQR) & $12(10-17)$ & $0(0-0)$ & $<0.01$ \\
\hline Chest radiographs & & & 0.76 \\
\hline Stable TB scar on chest $x$-ray & $11 / 156(7.1 \%)$ & $3 / 44(6.8 \%)$ & \\
\hline No stable TB scar on chest x-ray & $101 / 156(64.7 \%)$ & $31 / 44(70.5 \%)$ & \\
\hline No chest x-ray & $44 / 156(28.2 \%)$ & $10 / 44(22.7 \%)$ & \\
\hline Atopy* & & & 0.18 \\
\hline Non-atopic & $53 / 156(34.0 \%)$ & $21 / 44(47.7 \%)$ & \\
\hline Intermediate & $19 / 156(12.2 \%)$ & $6 / 44(13.6 \%)$ & \\
\hline Atopic & $84 / 156(53.8 \%)$ & $17 / 44(38.6 \%)$ & \\
\hline Asthma** & $26 / 135(19.3 \%)$ & $14 / 40(35.0 \%)$ & 0.04 \\
\hline Positive bronchodilator response & $15 / 90(16.7 \%)$ & $9 / 31(29.0 \%)$ & 0.14 \\
\hline Positive provocation testing & $15 / 106(14.2 \%)$ & $6 / 22(27.3 \%)$ & 0.13 \\
\hline
\end{tabular}


Table 2. The association between atopy and BCG scar.

\begin{tabular}{|c|c|c|c|c|c|}
\hline \multirow[t]{2}{*}{ Variables } & \multirow[t]{2}{*}{ Atopy status } & \multicolumn{2}{|l|}{ Unadjusted estimates } & \multicolumn{2}{|l|}{ Adjusted estimates } \\
\hline & & cOR $(95 \% \mathrm{CI})$ & p-value & aOR $(95 \% \mathrm{CI})$ & p-value \\
\hline \multicolumn{6}{|l|}{ Model 1* } \\
\hline \multirow[t]{3}{*}{ Age $(x+1$ vs. $x)$, years } & Non-atopy & 1 & & 1 & \\
\hline & Intermediate & $0.97(0.94,1.00)$ & 0.06 & $0.97(0.94,1.00)$ & 0.050 \\
\hline & Atopy & $0.92(0.892,0.94)$ & $<0.01$ & $0.91(0.89,0.94)$ & $<0.01$ \\
\hline \multirow[t]{3}{*}{ Male $v s$. Female sex } & Non-atopy & 1 & & 1 & \\
\hline & Intermediate & $2.40(0.95,6.07)$ & 0.06 & $2.56(0.99,6.58)$ & 0.051 \\
\hline & Atopy & $3.38(1.79,6.37)$ & $<0.01$ & $3.65(1.72,7.74)$ & 0.001 \\
\hline \multirow[t]{3}{*}{ BCG scar (+) vs. BCG scar (-) } & Non-atopy & 1 & & 1 & \\
\hline & Intermediate & $1.25(0.44,3.58)$ & 0.67 & $0.83(0.26,2.60)$ & 0.75 \\
\hline & Atopy & $1.96(0.95,4.05)$ & 0.07 & $0.89(0.33,2.37)$ & 0.81 \\
\hline \multicolumn{6}{|l|}{ Model 2** } \\
\hline \multirow[t]{3}{*}{ Age $(x+1$ vs. $x)$, years } & Non-atopy & 1 & & & \\
\hline & Intermediate & $0.97(0.94,1.00)$ & 0.06 & $0.97(0.94,1.00)$ & 0.05 \\
\hline & Atopy & $0.92(0.89,0.94)$ & $<0.01$ & $0.91(0.89,0.94)$ & $<0.01$ \\
\hline \multirow[t]{3}{*}{ Male $v s$. Female sex } & Non-atopy & 1 & & & \\
\hline & Intermediate & $2.40(0.95,6.07)$ & 0.064 & $2.57(0.99,6.67)$ & 0.06 \\
\hline & Atopy & $3.38(1.79,6.37)$ & $<0.001$ & $3.71(1.74,7.94)$ & $<0.01$ \\
\hline \multirow[t]{3}{*}{ BCG scar size $(x+1$ vs. $x), \mathrm{mm}$} & Non-atopy & 1 & & & \\
\hline & Intermediate & $1.01(0.96,1.06)$ & 0.681 & $1.00(0.95,1.07)$ & 0.79 \\
\hline & Atopy & $1.00(0.97,1.04)$ & 0.986 & $0.99(0.95,1.05)$ & 0.91 \\
\hline
\end{tabular}

cOR, crude odds ratio; $\mathrm{CI}$, confidential interval; aOR, adjusted odds ratio.

* Multinomial logistic regression model containing age, sex and the presence of BCG scar for adjusted estimates

** Multinomial logistic regression model containing age, sex and the size of BCG scar for adjusted estimates

Table 3. The association between asthma and BCG scar.

\begin{tabular}{|c|c|c|c|c|}
\hline \multirow[t]{2}{*}{ Variables } & \multicolumn{2}{|c|}{ Unadjusted estimates } & \multicolumn{2}{|c|}{ Adjusted estimates } \\
\hline & cOR $(95 \% \mathrm{CI})$ & p-value & aOR $(95 \% \mathrm{CI})$ & p-value \\
\hline \multicolumn{5}{|l|}{ Model 1* } \\
\hline Age $(x+1$ vs. $x)$, years & $0.99(0.97,1.01)$ & 0.29 & $0.97(0.95,1.00)$ & 0.047 \\
\hline Male vs. Female sex & $0.59(0.29,1.22)$ & 0.15 & $0.52(0.24,1.11)$ & 0.09 \\
\hline BCG scar (+) vs. BCG scar (-) & $0.44(0.20,0.96)$ & 0.04 & $0.33(0.14,0.77)$ & 0.01 \\
\hline \multicolumn{5}{|l|}{ Model 2** } \\
\hline Age $(x+1$ vs. $x)$, years & $0.99(0.97,1.01)$ & 0.29 & $0.98(0.96,1.00)$ & 0.13 \\
\hline Male $v s$. Female sex & $0.59(0.29,1.22)$ & 0.15 & $0.59(0.28,1.26)$ & 0.17 \\
\hline BCG scar size $(x+1$ vs. $x), \mathrm{mm}$ & $0.94(0.89,0.99)$ & 0.01 & $0.94(0.89,0.99)$ & 0.01 \\
\hline
\end{tabular}

cOR, crude odds ratio; $\mathrm{CI}$, confidential interval; aOR, adjusted odds ratio.

* Binary logistic regression model containing age, sex and the presence of BCG scar for adjusted estimates

** Binary logistic regression model containing age, sex and the size of BCG scar for adjusted estimates

\section{Discussion}

In this study, we did not find a significant association between the presence or size of BCG scar and atopy. However, the presence of a BCG scar showed a negative relationship with asthma.

We used the presence of scar(s) as an indicator of BCG vaccination. Since 1952, a systemic BCG vaccination program was introduced in South Korea and all children had been vaccinated with BCG Pasteur by the intradermal method. As a result of South Korea's liberalized import action since the 1990s, BCG vaccines such as BCG Tokyo, which is administered percutaneously, were also introduced. Considering the age range of participants in this study, most of the study population are intradermal BCG vaccine recipients. BCG vaccination using an intradermal method commonly results in a distinctive scar, compared to administration via subcutaneous methods [17, 18], and therefore a BCG scar on an appropriate area of the body can be used as an indicator of BCG vaccination. A study showing the protective effect of BCG vaccination against pulmonary tuberculosis among Korean adults also used the scar as an indicator of BCG vaccination [19]. Moreover, it is difficult to get information regarding BCG vaccination status from adults as the BCG vaccination is administered in the neonatal period, and adults may be unaware of their vaccination status. Studies have shown that tissue reactions at the site of the BCG vaccination are proportional to the production of IFN- $\gamma$ in response to the mycobacterial antigen in the vaccine $[20,21]$. Therefore, the resulting scar diameter might be a useful measure of the immune response to the BCG vaccine, as well as Th1 lymphocyte activity, which has an inhibitory effect on Th2 lymphocytes and induction of allergy. 
With the immunological background, there have been clinical studies evaluating the association between BCG status and allergic diseases. A recent meta-analysis demonstrated that BCG vaccination was unlikely to be associated with protection against the risk of allergic sensitization and disease, but was associated with a protective effect against the risk of asthma [22]. Researchers have also shown an inverse relationship between the diameters of BCG scars and asthma in children [23-25]. However, a study conducted in China by Ma et al. [26] showed no significant difference in BCG scar size between asthmatic and normal children, although children in rural areas had significantly lower scar diameters than urban children. Moreover, there are few studies reporting the association between BCG vaccination and atopy or asthma in adult populations. Although we did not find a significant association between the presence or size of BCG scar and atopy, the presence of BCG scar showed a negative association with asthma in adults in our analysis of patients who had undergone bronchodilator response measurement or bronchial provocation testing.

The protective effect of BCG vaccination against asthma could be explained by the inhibitory effect on the Th2 immune response as mentioned above. One randomized controlled trial of BCG vaccination in adults with moderate-to-severe asthma demonstrated a significant improvement in pulmonary functions and reduction of medication use, accompanied by suppression of the Th2-type immune response [27]. As one study showed that the clinical effects of BCG vaccination persist for more than 60 years [13], and therefore those immunologic effects could be prolonged into adult life. A recent animal study has shown that neonatal BCG vaccination elicited long-term protection by inhibiting allergic airway inflammation mediated by the modulation of Th1/Th2 cytokine production in younger mice, but not in aged mice [28]. The investigators suggested that other mechanism(s) may be responsible for the long-lasting protection of BCG vaccination in aged mice, possibly related to regulatory $\mathrm{T}$ cells.

In this study population, we did not find any association between BCG vaccination and atopy. There are several possible explanations. First, as Linehan et al.'s meta-analysis showed [29], it may be possible that there is no relationship between BCG vaccination and allergic diseases other than asthma. The authors of the meta-analysis suggested that, given the failure to show evidence of protection against sensitization, the beneficial effect of BCG vaccination in preventing the development of asthma, although the effect was marginal, [29] assuming the effect is real, is unlikely to be related to atopic mechanisms. In addition, it has been reported that BCG could protect against lower respiratory tract infections and sepsis $[30,31]$. The protection against respiratory infection likely results from the modulation of the innate immune system [32]. Lower respiratory infections probably tend to promote asthma, whereas sepsis might protect against allergy and asthma [33]. Thus, BCG's protection against asthma might indirectly result from fewer respiratory infections, but fewer episodes of sepsis may mask the protective effect of BCG against atopy. It has also been reported that there is an increased frequency of IFN- $\gamma$-producing CD4 and CD8 T cells in asthmatic patients in comparison to normal subjects [34], suggesting that the Th1 responses may play a role in the pathogenesis of atopy, in contrast to the hygiene hypothesis. The small number of participants in our study did not allow for the analyses of various atopic statuses. Second, BCG administered early appears to protect against atopy compared to BCG administered later in infancy [4,35]. Many observational studies have included children vaccinated early and late, or of unknown age at vaccination, which adds considerable heterogeneity. Third, confounders might affect the results. Agarwal et al. [36] demonstrated that formation of a BCG scar depends on the vaccination strain and dosage, age, gender, method of immunization, training of administering health professionals, and response to the vaccine, while Santiago et al. [37] reported that scar size did not differ by sex, birth weight, or nutritional status in the first two months. It is possible that some of the above-mentioned confounding factors, which were not accounted for in this study, may be in part responsible for the diameter of the BCG scar. Fourth, ethnicity and genetic factors may have impacted the results [6]. Fifth, our study was underpowered to detect an association with atopy, thus there may be an association that we did not find. The increased power for asthma outcomes versus atopy was also evident in the meta-analysis, with 17 studies for asthma and 7 for SPTs [29].

Our study has some limitations. First, it is possible that there was some selection bias affecting classification of asthma. As this is a retrospective study, the number of participants was chosen for convenience. But such a bias would not be expected to have affected the association between BCG and asthma/atopy. Second, the influence of age and sex might not be sufficiently controlled, although multivariable analyses adjusted for age and sex were performed. Third, we did not completely exclude patients with chronic obstructive pulmonary disease (COPD). As COPD patients are likely to have been classified as cases with asthma, a misclassification of 'non-cases' as 'cases' would dilute any effect and could lead to bias 
the results toward no association. Fourth, we used different criteria for the diagnosis of asthma including a methacholine test, mannitol test, and spirometry. The analysis to determine the association between BCG scar and asthma was performed only on those individuals who underwent spirometry with post-bronchodilator measurement or bronchial provocation test. We also recognize that the use of the $\mathrm{A} / \mathrm{H}$ ratio as a diagnostic criterion of atopy [38] might be another weakness because atopy is usually defined based on size [39].

In conclusions, although there was no significant association between BCG scar and atopy in this study, BCG scar was inversely associated with asthma as diagnosed by either provocation testing or bronchodilator reversibility among Korean adults. Further prospective studies are necessary to clarify the effect of BCG on the development of asthma, and there are ongoing prospective studies [40].

\section{Acknowledgements}

Sung Soo Park analyzed data and wrote the paper. Eun Young Heo, Deog Kyeom Kim and Hee Soon Chung performed research and collected data. Chang-Hoon Lee designed the study and wrote the paper.

\section{Competing Interests}

The authors have declared that no competing interest exists.

\section{References}

1. Strachan DP. Hay fever, hygiene, and household size. BMJ. 1989; 299(6710): 1259-60.

2. Rook GA, Hernandez-Pando R. Immunological and endocrinological characteristics of tuberculosis that provide opportunities for immunotherapeutic intervention. Novartis Found Symp. 1998; 217: 73-87.

3. Shirakawa T, Enomoto T, Shimazu S, Hopkin JM. The inverse association between tuberculin responses and atopic disorder. Science. 1997; 275(5296): 77-9.

4. Aaby P, Shaheen SO, Heyes CB, Goudiaby A, Hall AJ, Shiell AW, et al. Early BCG vaccination and reduction in atopy in Guinea-Bissau. Clin Exp Allergy. 2000; 30(5): 644-50.

5. Alm JS, Lilja G, Pershagen G, Scheynius A. Early BCG vaccination and development of atopy. Lancet. 1997; 350(9075): 400-3.

6. Gruber C, Meinlschmidt G, Bergmann R, Wahn U, Stark K. Is early BCG vaccination associated with less atopic disease? An epidemiological study in German preschool children with different ethnic backgrounds. Pediatr Allergy Immunol. 2002; 13(3): 177-81.

7. Krause TG, Hviid A, Koch A, Friborg J, Hjuler T, Wohlfahrt J, et al. BCG vaccination and risk of atopy. JAMA. 2003; 289(8): 1012-5.

8. Marks GB, Ng K, Zhou J, Toelle BG, Xuan W, Belousova EG, et al. The effect of neonatal BCG vaccination on atopy and asthma at age 7 to 14 years: an historical cohort study in a community with a very low prevalence of tuberculosis infection and a high prevalence of atopic disease. J Allergy Clin Immunol. 2003; 111(3): 541-9.

9. Strannegard IL, Larsson LO, Wennergren G, Strannegard O. Prevalence of allergy in children in relation to prior BCG vaccination and infection with atypical mycobacteria. Allergy. 1998; 53(3): 249-54

10. Wong GW, Hui DS, Tam CM, Chan HH, Fok TF, Chan-Yeung M, et al. Asthma, atopy and tuberculin responses in Chinese schoolchildren in Hong Kong. Thorax. 2001; 56(10): 770-3.

11. Silverman M. BCG vaccination and atopy--unfinished business? Lancet. 1997; 350(9075): 380-1

12. Vargas MH, Bernal-Alcantara DA, Vaca MA, Franco-Marina F, Lascurain R. Effect of BCG vaccination in asthmatic schoolchildren. Pediatr Allergy Immunol. 2004; 15(5): 415-20.
13. Aronson NE, Santosham $M$, Comstock GW, Howard RS, Moulton LH, Rhoades ER, et al. Long-term efficacy of BCG vaccine in American Indians and Alaska Natives: A 60-year follow-up study. JAMA. 2004; 291(17): 2086-91.

14. Barreto ML, Cunha SS, Pereira SM, Genser B, Hijjar MA, Yury Ichihara M, et al. Neonatal BCG protection against tuberculosis lasts for 20 years in Brazil. Int J Tuberc Lung Dis. 2005; 9(10): 1171-3.

15. Sverrild A, Porsbjerg C, Thomsen SF, Backer V. Diagnostic properties of inhaled mannitol in the diagnosis of asthma: a population study. J Allergy Clin Immunol. 2009; 124(5): 928-32 e1.

16. Crapo RO, Casaburi R, Coates AL, Enright PL, Hankinson JL, Irvin CG, et al. Guidelines for methacholine and exercise challenge testing-1999. This official statement of the American Thoracic Society was adopted by the ATS Board of Directors, July 1999. Am J Respir Crit Care Med. 2000; 161(1): 309-29.

17. WHO Tuberculosis Research Office. Suppurative lymphadenitis following intradermal BCG vaccination of preschool children. Bull World Health Organ. 1955; $12:$ 143-67.

18. ten Dam HG. Research on BCG vaccination. Adv Tuberc Res. 1984; 21:79-106.

19. Jin BW, Hong $\mathrm{YP}$, Kim SJ. A contact study to evaluate the BCG vaccination programme in Seoul. Tubercle. 1989; 70(4): 241-8.

20. Hoft DF, Leonardi C, Milligan T, Nahass GT, Kemp B, Cook S, et al. Clinical reactogenicity of intradermal bacille Calmette-Guerin vaccination. Clinical Infectious Diseases. 1999; 28(4): 785-90.

21. Kemp EB, Belshe RB, Hoft DF. Immune responses stimulated by percutaneous and intradermal bacille Calmette-Guerin. Journal of Infectious Diseases. 1996; 174(1): 113-9.

22. Arnoldussen DL, Linehan $M$, Sheikh A. BCG vaccination and allergy: a systematic review and meta-analysis. J Allergy Clin Immunol. 2011; 127(1): 246-53.

23. Ahmadiafshar A, Parchegani MR, Moosavinasab N, Koosha A. A Study of Relation between BCG Scar and Atopy in Schoolchildren of Zanjan City. Iran J Allergy Asthma Immunol. 2005; 4(4): 185-8.

24. Rehman A, Ullah I. The BCG scar size in asthmatic and non-asthmatic children. J Pak Med Assoc. 2009; 59(9): 625-8.

25. Sarinho E, Schor D, Veloso M, Lima M. BCG scar diameter and asthma: a case-control study. J Allergy Clin Immunol. 2000; 106(6): 1199-200.

26. Ma Y, Li XF, Zhao J, Wong GW, Zhou CS, Chen YZ. [Relationships between the diameters of Bacille Calmette-Guerin scars and asthma, atopy in urban and rural Beijing children]. Zhonghua Jie He He Hu Xi Za Zhi. 2003; 26(9): 526-30.

27. Choi IS, Koh YI. Therapeutic effects of BCG vaccination in adult asthmatic patients: a randomized, controlled trial. Ann Allergy Asthma Immunol. 2002; 88(6): 584-91.

28. Shen $\mathrm{H}$, Huang $\mathrm{H}$, Wang J, Ye S, Li W, Wang $\mathrm{K}$, et al. Neonatal vaccination with Bacillus Calmette-Guerin elicits long-term protection in mouse-allergic responses. Allergy. 2008; 63(5): 555-63.

29. Linehan MF, Nurmatov U, Frank TL, Niven RM, Baxter DN, Sheikh A. Does BCG vaccination protect against childhood asthma? Final results from the Manchester Community Asthma Study retrospective cohort study and updated systematic review and meta-analysis. J Allergy Clin Immunol. 2014; 133(3): 688-95 e14

30. de Castro MJ, Pardo-Seco J, Martinon-Torres F. Nonspecific (Heterologous) Protection of Neonatal BCG Vaccination Against Hospitalization Due to Respiratory Infection and Sepsis. Clin Infect Dis. 2015.

31. Aaby P, Roth A, Ravn H, Napirna BM, Rodrigues A, Lisse IM, et al. Randomized trial of BCG vaccination at birth to low-birth-weight children: beneficial nonspecific effects in the neonatal period? J Infect Dis. 2011; 204(2): 245-52.

32. Netea MG, van Crevel R. BCG-induced protection: effects on innate immune memory. Semin Immunol. 2014; 26(6): 512-7.

33. Cetinkaya F, Uslu HS, Nuhoglu A. Effect of neonatal sepsis on the development of allergies and asthma in later childhood. Int Arch Allergy Immunol. 2007; 142(2): 145-50.

34. Cho SH, Stanciu LA, Begishivili T, Bates PJ, Holgate ST, Johnston SL. Peripheral blood CD4+ and CD8+ T cell type 1 and type 2 cytokine production in atopic asthmatic and normal subjects. Clin Exp Allergy. 2002; 32(3): 427-33.

35. Kiraly N, Benn CS, Biering-Sorensen S, Rodrigues A, Jensen KJ, Ravn H, et al. Vitamin A supplementation and BCG vaccination at birth may affect atopy in childhood: long-term follow-up of a randomized controlled trial. Allergy. 2013; 68(9): 1168-76.

36. Agarwal RK, Kapur D, Kumari S. Development of BCG scar in relation to the age and nutritional status. Indian Pediatr. 1990; 27(3): 291-3.

37. Santiago EM, Lawson E, Gillenwater K, Kalangi S, Lescano AG, Du Quella G, et al. A prospective study of bacillus Calmette-Guerin scar formation and tuberculin skin test reactivity in infants in Lima, Peru. Pediatrics. 2003; 112(4): e298.

38. Scichilone N, Callari A, Augugliaro G, Marchese M, Togias A, Bellia V. The impact of age on prevalence of positive skin prick tests and specific IgE tests. Respir Med. 2011; 105(5): 651-8.

39. Bernstein IL, Li JT, Bernstein DI, Hamilton R, Spector SL, Tan R, et al. Allergy diagnostic testing: an updated practice parameter. Ann Allergy Asthma Immunol. 2008; 100(3 Suppl 3): S1-148.

40. Kiraly N, Allen KJ, Curtis N. BCG for the prevention of food allergy exploring a new use for an old vaccine. Med J Aust. 2015; 202(11): 565-6. 